\title{
Vivências de apreciação, improvisação e composição erm sala de aula
}

Roveli Bichels

Gislene Natera 
O presente artigo consiste em um relato das atividades de apreciação, improvisação e composição desenvolvidas no estágio curricular do curso de Licenciatura em Música, com turmas de quarto e quinto anos em uma escola da Rede Municipal de ensino de Florianópolis (SC). As atividades foram elaboradas segundo o estabelecido no planejamento anual do professor supervisor e na matriz curricular da Rede Municipal. Neste contexto, as atividades musicais foram planejadas para proporcionar aos estudantes a vivência com a canção africana, a improvisação e a composição, com o objetivo de fomentar a criatividade, a identidade e o fazer musical coletivo. Conclui-se que é importante que o professor liberte-se das amarras de um ensino musical dito tradicional e que os estudantes precisam passar por múltiplas vivências para que consigam analisar, repensar e redefinir conceitos relacionados ao fazer artístico, além de desenvolver sua percepção e capacidade de apreciação musical.

Palavras-chave: Educação musical; Composição; Improvisação.

\section{Introdução}

$\mathrm{O}$ presente artigo compartilha parte das atividades desenvolvidas com as turmas de quarto e quinto anos do ensino fundamental, com faixa etária entre nove e doze anos, envolvendo apreciação, improvisação e composição, elaboradas e postas em prática no âmbito do estágio curricular supervisionado do curso de Licenciatura em Música da Universidade do Estado de Santa Catarina.

$\mathrm{O}$ estágio foi realizado em uma escola da rede municipal de ensino da cidade de Florianópolis (SC), na qual estudam aproximadamente seiscentas crianças. A escola oferece o Ensino Fundamental I (turmas do $1^{\circ}$ ao $5^{\circ}$ ano) no período matutino e vespertino, atendendo assim grande parte das crianças residentes em seu entorno.

As aulas de música costumam ser ministradas na própria sala de aula de cada turma. Porém, há uma sala de vídeo/auditório que também se apresenta como opçáo de espaço e que pode ser utilizada mediante agendamento. Os equipamentos e instrumentos musicais disponíveis 
consistem em violão, caixa amplificada, aparelho de som, flautas e instrumentos de percussão, como tambores e chocalhos, que são acomodados na sala dos professores. Vale ressaltar que os materiais e instrumentos musicais utilizados em cada aula devem ser escolhidos e deslocados para o espaço de atuação antecipadamente pelo professor supervisor e estagiários.

As propostas de atividades dos estagiários foram elaboradas tendo como base o planejamento anual do professor supervisor e a matriz curricular do município de Florianópolis (2008; 2012), que estabelece os conteúdos para o ensino de música nas escolas de sua rede de ensino. Consta na matriz curricular que o ensino de música deve contemplar três grandes eixos da Educação Musical: a apreciação (contextualização); execução (cantar e tocar) e criação musical (improviso e composição). Da mesma forma, nos objetivos de conhecimento específicos para o $4^{\circ}$ e $5^{\circ}$ anos consta a necessidade de incluir obras musicais de diferentes culturas e origens com ênfase na música étnica brasileira e de diferentes naçóes.

Assim como Almeida e Pucci (2002), nós concordamos com a inclusão da música africana no contexto escolar porque entendemos que ela nos permite ampliar os horizontes de nossos alunos, possibilitando uma discussão em torno da ideia de que náo existe uma música melhor que a outra, de que precisamos analisar a música dentro do contexto que ela está inserida; que ela é reconhecida mundialmente pela sua polirritmia rica e complexa de seus tambores, mas também pela sua suavidade nas kalimbas, nas formas cíclicas, no canto contrapontístico dos pigmeus e nos sons das cítaras de 21 cordas. Ou seja, a música africana

[...] tem a capacidade de se combinar com outros estilos e tendências tanto pela sua riqueza quanto pela sua simplicidade. Pulso firme, ritmos cadenciados e melodias de fácil memorização são elementos que fazem dessa música fonte inesgotável de pesquisas e de empréstimos de todos os tipos (ALMEIDA; PUCCI, 2002, p. 96).

\footnotetext{
${ }^{7}$ Vale ressaltar também a participação, nas atividades do estágio, de nosso colega Emanuel Souza Pereira, que muito contribuiu com sua alegria e disponibilidade de levar convidados e diferentes instrumentos para o nosso contexto escolar. Fica aqui nosso agradecimento.
} 
Buscando trazer esse contexto africano para a sala de aula, necessitamos dialogar com Carvalho (2010), que afirma que a disposição em círculo para as reuniōes é muito freqüente na África Negra. Segundo a autora, desta forma os participantes sentem-se igualmente fazendo parte do coletivo e, havendo a necessidade de alguém estar ao centro para se colocar, este poderá ser percebido com facilidade pelos demais. Ainda de acordo com a autora, simbolicamente o círculo representa a relação do indivíduo africano com seus antepassados, seus parentes e consigo mesmo. A música está diretamente ligada às questốes da vida social e religiosa, aos mitos, magias e ritos de passagem, estando associada à coletividade e não à performance individual. Fazendo parte desta percepção de mundo não fragmentada, holística, a prática musical está associada a um processo que visa determinado fim (CARVALHO, 2010).

Com essa fundamentação, buscamos reservar o espaço da sala de vídeo/auditório sempre que possível, possibilitando que sentássemos todos em um grande círculo, tivéssemos mais liberdade de ação e interação nas atividades, facilitando também a comunicação visual e a percepção do outro.

Percebemos então que no decorrer de uma aula de música, os processos de apreciação, execução e criação/improvisação são definidos no próprio fazer musical ${ }^{8}$ e por todos os participantes, tornando-se um momento poético único e espontâneo, no qual é compartilhada a alegria de se fazer música, o respeito ao outro e a afirmação da identidade de cada um. Assim, é valorizado o processo e não o produto, o aspecto coletivo e náo o individual.

Iniciamos assim nossa aproximação com o contexto desenvolvido pelo professor supervisor: musica africana. Em nossas primeiras aulas, apresentamos cançóes africanas para se cantar, observar e realizar ritmos e melodias com instrumentos percussivos e melódicos (flauta) como, por exemplo: "Quem dorme e o Leão" (Walt Disney), com apresentação também da célula da canção tocada no contexto africano; "E-nhambo", "Sansa Kroma", etc., mas também trouxemos um convidado africano que tocou musicas em diferentes instrumentos africanos, mais especificamente, musicas de Cabo Verde.

Os tópicos seguintes relatam um pouco da experiência em atividades de improvisação seguidas das de composição durante o estágio curricular do curso de Licenciatura em Música.

${ }^{8}$ Para maiores detalhes ver: SMALL (1999) e CUSTODERO (2006). 


\section{Improvisação na sala de aula}

$A_{\text {criançasconhecessem experimentassemosdiferentesinstrumentos }}^{\text {s primeiras atividades de improvisacáo foram propostas para que as }}$ musicais de percussão disponíveis na escola. Para isso, foram utilizados os jogos de pergunta e resposta, em que, num dos possíveis formatos, uma idéia percussiva improvisada colocada como estímulo musical ou "pergunta" foi tocada pelo professor e as crianças "responderam" com uma imitação, cada qual com seu instrumento, escolhido antecipadamente. Após este primeiro momento, de apresentação da atividade,cadacriançaassumiuafunçãode "perguntador".Posteriormente, a resposta poderia não ser a imitação da pergunta, mas uma frase percussiva diferente, porém coerente, dentro das possibilidades musicais das crianças, exercitando desta forma a improvisação e o diálogo musical.

Estes jogos foram pensados a partir de uma das práticas da cultura musical africana conhecida como canto responsório, que atravésda diáspora negra acabou por influenciar, por exemplo, o samba, além de outras práticas e gêneros musicais, onde os povos da África Negra se estabeleceram. O canto responsório, como definem Bianquinch e Meirelles (2006, p. 224) "remete para o padrão de Chamamento e Resposta, frequentemente encontrado entre tribos africanas. Há um cantor que inicia o Chamamento e um coro que entoa, em uníssono, a Resposta”.

Nos jogos de pergunta e resposta, além de se trabalhar a improvisação e a criatividade, também foram importantes a percepção das características sonoras dos timbres dos instrumentos de percussão disponíveis, a classificação entre tambores e chocalhos através da experimentação e audição, o ouvir a si mesmo e aos colegas, assim como o tocar em grupo e o momento de náo tocar.

Com os jogos e a prática da improvisação buscamos desenvolver a capacidade de responder musicalmente o mais rápido e coerente possível a uma "pergunta musical", seja ela através de sons instrumentais ou corporais. Dessa forma, trouxemos para a sala de aula "uma das características também bastante marcante na música africana que é a relação direta entre a música e a dança” (ALMEIDA; PUCCI, 2002, p. 98). Vale ressaltar também que a música de candomblé, a capoeira, os maracatus, as congadas entre outras manifestaçóes populares, segundo as autoras, são exemplos da fusão da música com a dança e da uniáo do sagrado com o profano. 
Em nossa opinião, é atribuída ao professor a função de pensar o sujeito numa perspectiva ampla, proporcionando práticas que dêem conta desta complexidade. Sendo assim, é interessante que sejam realizadas interlocuçóes entre estas várias formas de se fazer música, as diferentes maneiras de se fazer arte e também entre os variados campos do saber (traduzidos nas disciplinas escolares), para que se possa projetar uma atuação baseada na intermediação da construção do conhecimento, provocando e alimentando a criatividade e a curiosidade. Como resultado deste processo eatravés do julgamento crítico/reflexivo, acreditamos que o professor participa da formação de indivíduos mais criteriosos em sua apreciação não somente musical, mas artística, além de cidadãos conscientes e influentes na construção da sociedade. Assim, concordamos que é

[...] de fundamental importância, em todo o processo de educação musical, que nossos alunos desenvolvam a escuta musical de forma crítica, e se tornem consumidores e produtores de música conscientes, e que isto contribua para as futuras escolhas na sua vida como cidadáo (...). Destacamos a abordagem do conteúdo relacionado ao estudo da música em diferentes épocas e diferentes culturas, como uma fonte de trabalho para integração com outras disciplinas (FLORIANÓPOLIS, 2012, p. 12).

Enfim, na educação musical reflete-se muito sobre as abordagens que o professor precisa desenvolver para trabalhar com os mais diversos grupos de estudantes, reflexão que o convida a respeitar o significado que os mesmos atribuem à música por meio de sua cultura musical que, na maioria das vezes, é massificada pelos meios de comunicação. Neste contexto, tornou-se pertinente a nós o pensar uma educação que proporcionasse aos estudantes o contato com uma prática que os possibilitasse vivenciar e expressar idéias musicais com a improvisação, mas também com a composição, respeitando suas vivências e culturas pessoais, ao mesmo tempo em que também proporcionasse a eles a possibilidade de acessar outras culturas musicais historicamente presentes e influentes na música produzida em nosso país. 


\section{As atividades de composição}

Foram desenvolvidas duas atividades de composição com ambas as turmas. A primeira teve como referência um motivo rítmico com duas células, envolvendo as figuras semínima e colcheia, extraído de uma das músicas do repertório africano trabalhado nas aulas. Nesta atividade, as crianças, em grupos de três ou quatro, compuseram seus fragmentos rítmicos utilizando tais células. O primeiro momento foi o de apresentar a composiçáo aos colegas por meio de instrumentos de percussão e, o segundo, o de utilizar as composiçóes como "pergunta", no jogo de pergunta e resposta. A segunda atividade proposta foi a elaboraçáo, a partir de um modelo, de uma poesia/letra de música com duas quadras, partindo do tema "escola".

Após a realização destas atividades, uma das questốes sobre as quais refletimos foi com relação aos modelos dados para referenciar as composiçóes e de que forma estes influenciaram os trabalhos. $\mathrm{Na}$ primeira atividade, um dos grupos "elaborou" sua composição exatamente igual ao modelo (figuras 1 e 2):

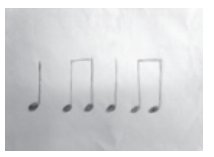

Figura 1: Referencial para as composições.

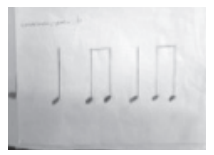

Figura 2: Composição de um dos grupos.

Alguns trabalhos destacaram-se pela métrica, já que nos mesmos não foi levado em consideraçáo o compasso quaternário, que vinha sendo exercitado nas aulas (figuras 3 e 4). No trabalho reproduzido na figura 3, pode-se perceber que após algumas elaboraçóes, em tamanhos menores, o grupo chegou ao resultado que lhe pareceu interessante.

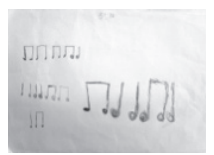

Figura 3: Elaboraçóes prévias.

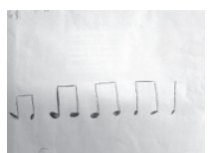

Figura 4: A questão métrica. 
Apesar de termos trabalhado as mesmas células rítmicas em aulas anteriores através da percussão e flauta, sempre considerando compasso quaternário e o evidenciando através da contagem, para alguns grupos esta questão pareceu não se sobressair. Ficamos com a impressão de que contar "um, dois, três, quatro" antes de iniciar um exercício, uma canção ou mesmo os exemplos de composiçóes, foi tomado como mera forma de "contar para começar".

Este exemplo nos faz pensar sobre como as informaçóes por vezes são recebidas pelas crianças de forma fragmentada e nos convida à busca de soluçóes a fim de melhorar a relação entre os conhecimentos. A questão da métrica não se caracteriza exatamente em um problema, talvez, nesta situação, muito pelo contrário. Nós estávamos em princípio preocupados em fazer com que as crianças compreendessem as fórmulas de compasso. Posteriormente nos pareceu muito interessante e pertinente perceber que algumas crianças não se importam em "emoldurar" uma idéia musical, simplesmente as têm e as executam de forma um tanto espontânea. Por outro lado, podemos pensar que a polirritmia ouvida em cançóes africanas de alguma forma sugeriu a liberdade, no que inocentemente chamaram "escrever a música no meu tempo".

Para exemplificar a segunda atividade de composição e ao mesmo tempo fornecer instruçôes sobre as quadras rimadas, criamos o seguinte exemplo:

Falem sobre algo que está na memória

O conhecimento que foi apreendido

Contem algum caso,

inventem uma história

Da hora do recreio, algo divertido
Eu canto essa estrofe como demonstração A parte repetida é chamada de refrão Gostamos da escola é o tema para vocês

Criem uma estrofe, agora é a sua vez

Após elaborarem suas composiçōes, as crianças também, em grupos de três ou quatro, foram convidadas a apresentá-las aos colegas de sala, com acompanhamento dos estagiários, no intuito de experimentar um momento de expressão musical, além de um exercício de afirmação da identidade. Além do exercício de criação, as composiçóes refletiram a impressão que estas crianças têm da escola e, mesmo que o modelo tenha procurado incentivá-los para os aspectos positivos da mesma, a liberdade de expressão trouxe produçóes que mostraram outros pontos de vista. Abaixo dois exemplos: 
Tenho tédio da escola

Ela da vontade de enjoar

Quando eu chego em casa

Eu só quero descansar

Todo dia tenho que estudar

Mesmo que desmaiar

Se não passar no vestibular

Você não vai trabalhar
Tenho raiva da escola

Todo dia eu vou pra lá

Mas se um dia eu faltar

Eu vou mesmo reprovar

A escola me dá nos nervos

E na minha sala só tem pentelho

Sorte que meus amigos estáo lá

Para me ajudar

Nestes versos é possível observar que as crianças não se intimidaram em manifestar seu ponto de vista com relação à escola e às questóes ligadas ao conhecimento e sua pertinência para a vida adulta. As apresentaçóes dos grupos foram recebidas de forma respeitosa pelos demais colegas, no entanto, abriram espaço para que nós, educadores, refletíssemos posteriormente acerca das questóes levantadas pelas crianças e da crítica que escreveram sobre a escola. Outro ponto a ser pensado é o uso de modelos para as composiçóes, que podem ser utilizados de forma a não negar ou oprimir a identidade criativa das crianças.

Outras composições, no entanto, revelaram um carinho em relação à escola:

Gostamos da escola porque no recreio vamos nos divertir

Vamos tirar o bullying da escola, ensinar a não agredir

Vamos nos comportar nas aulas não incomodar Quando o professor precisar vamos ajudar

A aula de música é legal, o professor traz um instrumento no final Na quinta-feira tem ciências e no final bate o sinal Quando chego em casa brinco até o fim Acordo bem cedinho e vou para a escola sim 


\section{Considerações finais}

Tm dos objetivos de se trazer para as aulas de música as relaçóes entre apreciação, improvisação, composição e as práticas musicais africanas como fio condutor era o de motivar as crianças a conhecerem outros ambientes e formas de se fazer música, outros lugares ou pontos de apreciação e interpretação das obras musicais e sua finalidade, ampliando a percepçáo e o entendimento sobre a arte musical, assim como a experiência estética em sentido mais amplo.

A partir deste relato pode-se considerar que o professor/educador musical necessita de uma reflexão e pesquisa anterior e posterior a cada prática docente, ao mesmo tempo em que deve conhecer ao máximo as possibilidades circunstanciais dos estudantes, além de outras maneiras de se fazer e pensar em música, outras culturas e suas formas de produção artística. No contexto escolar, é importante que o professor liberte-se das amarras de um ensino musical dito tradicional, no qual muitas vezes o objetivo é formar instrumentistas, pensando unicamente em um resultado e não no processo.

Em nossa opinião, é fundamental considerar que os estudantes precisam passar por múltiplas vivências para aprender a analisar, repensar e redefinir conceitos relacionados ao fazer artístico, além de desenvolver sua percepção e capacidade de apreciação. Quando suas capacidades e vivências sáo levadas em conta no processo de educação musical, possibilita-se uma rica troca de experiências e impressóes estéticas, além da construção da identidade do grupo baseada no respeito à alteridade. 


\section{Referências}

ALMEIDA, M. Berenice de.; PUCCI, Magda. Outras terras, outros sons. São Paulo: Callis, 2002.

BIANQUINCH, Jean-Paul Bacoly; MEIRELLES, Regina. A cultura Bassari. In: TUGNY, Rosângela Pereira de; QUEIROZ, Ruben Caixeta de (Org.). Músicas africanas e indígenas no Brasil. Belo Horizonte: Editora da UFMG, 2006, p. 213-226.

CARVALHO, Lilian Rocha de Abreu Sodré. Música africana na sala de aula: cantando, tocando e dançando nossas raizes negras. São Paulo: Duna Dueto, 2010.

CUSTODERO Lori Almeida. A. Buscando desafios, encontrando habilidades: a experiência de fluxo e a educação musical. In: ILARI, Beatriz S. (Org.). Em busca da mente musical. Curitiba: Ed. Da UFPR, 2006, p. 388.

FLORIANÓPOLIS. Secretaria Municipal de Educação. Departamento de Educação Fundamental. Proposta Curricularl Prefeitura Municipal de Florianópolis. Florianópolis, 2008.

FLORIANÓPOLIS. Secretaria Municipal de Educação. Ensino Fundamental de 09 anos. Florianópolis, 2012.

SMALL, Christopher. El musicar: un ritual en el espacio social. Revista Transcultural de Música, n.4, 1999, p. 1-16. 